segregating families and so be led to an understanding of sampling variation and tests of goodness of fit. Finally, the bearings of genetics on evolutionary theory and taxonomy should be made clear, with special reference to complex, or polygenic, inheritance. This would require that the teachers themselves should have studied the problem carefully, and should have "some form of belief and not merely a chaos" in their minds. Dr. Burns also recorded a protest against the tyranny of the herbarium method and a plea for a fuller studv of living plants in taxonomy.

With reference to the plant preeder, it is clear that he should receive a fuller mathematical training than the other classes of student, for otherwise he must acquire it "painfully, perhaps self-taught" at a later and less convenient stage. He should also have a more comprehensive course in genetics, though it could be modelled on the lines sketched earlier. $\mathrm{He}$ would require an introduction to the modern theory and practice of field experiments, with practical work involving responsibility for an actual trial. The part to be played by statistics was discussed in relation to the danger of an undue adherence to statistical methods leading to a neglect of the living plants. The solution is essentially that of training the breeder to rely primarily on observations of, and familiarity with, his erop; and to show him how his observations can be amplified and checked by statistical analyses.

Dr. Burns concluded with a survey of the present position of genetics teaching in India, which he found far from satisfactory. He advocated the giving of preliminary instruction in the universities and of advanced courses in agricultural institutes. Above all, if this genetical teaching is to be fruitful the students must be led to grow plants and study them as living things. The provision of facilities for this should not be too great a tax on the resources of educational establishments ; but there is a need for a small hand-book of practical genetics using the plants, chillies, rice, etc., with which Indians are familiar.

This discussion of teaching in plant genetics is noteworthy in a variety of ways, but especially perhaps for its insistence on the following points :

(1) The argument for the wider teaching and appreciation of general biology and the genetical point of view.

(2) The introduction of perspective into genetics by the approach through observable variation in Nature and the linking of genetics to evolutionary theory and taxonomy.

(3) The need for preliminary courses in floral biology and mathematics, and the introduction of modern statistical methods into the teaching.

(4) The emphasis on relating genetics teaching to the living organism as a corrective to over-formalization.

It must be remembered that Dr. Burns was discussing plant genetics in India, and so his various points may not apply with equal emphasis to all genetics in all countries. His separation of cytology from genetics and its inclusion in the botany course, for example, will not be desirable ev́erywhere. Nevertheless, his conclusions and proposals merit the careful study of all who are concerned with genetics and its teaching. His remarks are indeed especially timely in view of the expansion of genetics and genetical teaching which must now be contemplated in Great Britain.

\section{GEOLOGISTS IN THE POST-WAR PERIOD}

$\mathrm{T}$ HE total number of British geologists wholly engaged in a professional capacity in pre-war years was probably less than six hundred, nearly one quarter of whom were occupied in the teaching of the science, principally in the universities. To some extent this high proportion of geologists engaged in academic spheres is due to the fact that large classes of technical students in mining, metallurgy, civil engineering, and agriculture require tuition in geology as a part of their professional training.

The Geological Society of London has recently given evidence on the post-war recruitment of professional geologists, to the Inter-Departmental Committee on Further Education and Training, under the chairmanship of Lord Hankey. After expressing the hope that geology should be introduced into the schools as a fundamental study in general science courses, the Society stressed the important part that geologists play in the discovery and development of mining fields and oilfields, and in many branches of civil engineering.

In spite of the importance of geological work, the normal pre-war number of fully-trained geologists graduating each year from British universities is only about thirty. Although there have been wide fluctuations in the demand for mining and oil geologists, as a result of trade cycles, the supply of suitable men has usually been inadequate. It is probable that there will be a still greater dearth of British-trained geologists in the immediate post-war period, owing to the requirements of industry, Government Geological Surveys, and university teaching staffs. Within two years after the cessation of hostilities, it seems likely that considerably more than a hundred recruits will be called for to fill gaps and augment the ranks of professional geologists. It is certain that as soon as the War ends, there will be a demand for more men on the Geological Survey of Great Britain and the Colonial Geological Surveys.

Owing to impending retirements and proposed expansion of staff, there will be an immediate call for not less than ten men on the Geological Survey of Great Britain, with further recruitment in succeeding years. Representations have been made to the Secretary of State for the Colonies by the Geological Society and the Institution of Mining and Metallurgy, and it is confidently anticipated that many additional geologists will be enrolled for the staffs of the Colonial Geological Surveys. Not only is there a need for pressing on with routine geological mapping in the Colonies, but there is also great scope for more work to be done in connexion with the development of mineral resources, water supply, public works (dams, reservoirs, harbours, roads, etc.), and soil conservation. It has also been pointed out that several heads of university geological departments must soon be retiring under the age limit, and a number of junior posts in these departments will also be vacant. Within recent years new avenues of employment for geologists in industry have been opening up.

There are ample opportunities for trained geologists in the British oil companies, which face immediate post-war projects necessitating the employment of geological staffs larger than heretofore. Oilfields in Burma and elsewhere in the Far East will have to be re-opened, and studies must be made of the effect of Japanese operations, and of the best means of re- 
suscitating the oilfields. To offset damage to operating fields, exploration to discover new ones must be accelerated. British interests, whether co-operating or competing with those of the United States, must enlarge their fields of action, and they will need to engage large staffs of oil geologists to do this effectively. Moreover, geologists in oil companies are continually being attracted out of the exploratory phase into production and field management.

In addition, after the War there is likely to be a widespread development of young mining fields and a general exploration for new metallic and nonmetallic mineral deposits, which will involve the services of many mining geologists. Such men must also be recruited into the Government Geological Surveys in greater numbers than has hitherto been the practice.

\section{GRAVITATION, ELECTROMAGNET- ISM, AND QUANTUM THEORY}

A RECENT paper by Einstein and Bargmann declared that "Ever since the theory of general relativity has been developed there has existed the problem of finding a unified theory of the physical field by some generalization of the relativistic theory of gravitation... a decisive modification of the fundamental concepts is unavoidable". Schrödinger ${ }^{2}$ has also explained the need for a generalization of Einstein's original postulates in order to unify the theories of gravitation, electromagnetism, and the mesonic field responsible for binding the nucleus. There is no danger of the work of Einstein and Schrödinger being overlooked, but there is great danger that what is apparently an investigation of great importance, namely, "The Theory of Indeterminate Space-Time", by F. R. Saxby, may be missed by physicists, as it appears not in any of the usual scientific journals, but in the Bulletin of the Research Laboratories of the National Cash Register Company (pp. 13-72, September 1943), of which laboratories he is mathematics staff engineer.

Mr. Saxby proceeds on something like the general lines of the recent work of Einstein and Schrödinger, being influenced, like them, by the variations introduced into the original relativity theory by Weyl and Eddington; but his treatment has one strikingly original feature, which seems to link up quantum theory with relativity. If this claim can be substantiated, a great advance has been made. As Schrödinger ${ }^{2}$ remarked : "At the back of our striving for a unitary field theory, the great problem awaic s us of bringing it into line with quantum theory. This point is still covered with deep mist."

It is difficult to give a summary of Saxby's paper without complicated mathematies, but at any rate it can be indicated how it is related to Schrödinger's investigations. Both agree that the first step is to assume, as a postulate, that a certain correspondence exists between two vectors at two neighbouring points of space, or more generally between two tensors at two neighbouring points of space-time. The relation assumed is of a special form, known technically as an 'affine connexion'. It contains sixty-four arbitrary coefficients. In Einstein's original theory there were certain additional assumptions which restricted these coefficients, in particular an assumption of symmetry. Both Schrödinger and Saxby emphasize the non-symmetric case, the former to account for the meson field, the latter to account for the quantum. In both cases the gravitational part of the theory is much the same as in Einstein's older theory, but there are novelties in the electro. magnetic part, particularly in Saxby's treatment, which differs radically from any previously given. It is claimed that the new theory links up the indeter. minism of the electromagnetic potentials with Heisenberg's principle of uncertainty.

Mr. Saxby admits that much has yet to be done in developing his theory, and it is to be hoped that he will be able to publish an account of it in periodicals usually taken by university libraries. Einstein's 'own new investigations ${ }^{1}$ go more deeply into the purely mathematical side of the correspondence between two tensors, but he says: "whether we have succeeded in approaching the solution of this physical problem [that is, that of a unified theory of physics] is still uncertain. The answer to this question depends, among other things, on a mathematical problem which we have not yet been able to solve".

H. T. H. Piaggio.

1 Einstein, A., and Bargmann, V., Ann. Math., 45, 1 (1944).

2 Schrödinger, E., Nature, 158, 572 (1944).

\section{IMPERIAL FORESTRY INSTITUTE, OXFORD}

$\mathrm{T}$

HE nineteenth annual report of the Imperial Forestry Institute, Oxford, for $1942-43$ is inevitably coloured by war conditions. It proves somewhat difficult for those interested but not connected with Oxford to distinguish the actual staff of the Department or School of Forestry from that of the Imperial Forestry Institute ; in other words, the part of the forestry staff maintained by the University of Oxford from its own funds as compared with the grants expended upon the Institute coming from Government sources, Forestry Commission, several Colonies, and so forth.

As the report remarks, the Forestry Commission has issued a White Paper (Cmd. 6447) on future forest policy in Great Britain, which has not yet received the sanction of the House of Commons. A Supplementary Report (Cmd. 6500. London: H.M. Stationery Office, 2d. net), dealing with the forest policy of private woodlands, was published early in 1944. There had been controversy on the proposals in the first White Paper for the treatment of the private landowner and his woodlands (which had provided the bulk of the timber and other forest materials required for the War) and considerable opposition became apparent throughout the country. A conference was held between the Forestry Commission and representatives of landowners and forestry societies, and the reconsidered proposals agreed upon, mainly connected with the help which could be granted to private landowners towards afforesting and re-afforesting their felled-over lands, were published in the Supplementary White Paper.

The portions of the White Paper alluded to in the Imperial Forestry Institute's report are the sections on education and research, which particularly concern the Institute. It appears that during the year the Committee for Forestry at Oxford considered a report on the future policy of the Institute drawn up by a sub-committee. 'The report was adopted with certain modifications, "but it was considered necessary to keep it pending the expected publication 